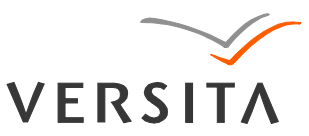

GEOCHRONOMETRIA 39(1) 2012: 48-56

DOI 10.2478/s13386-011-0049-y

VERSITA

\title{
PROPOSING NEW APPROACHES FOR DATING YOUNG VOLCANIC ERUPTIONS BY LUMINESCENCE METHODS
}

\author{
DANIEL RUFER ${ }^{1}$, EDWIN GNOS $^{2}$, RALPH METTIER ${ }^{1}$, FRANK PREUSSER $^{1,3}$ and GUIDO SCHREURS ${ }^{1}$ \\ ${ }^{1}$ Institute of Geological Sciences, University of Bern, Baltzerstrasse 1+3, 3012 Bern, Switzerland \\ ${ }^{2}$ Muséum d'histoire naturelle de Genève, route de Malagnou 1, CP 6434, 1211 Genève, Switzerland \\ ${ }^{3}$ Department of Physical Geography and Quaternary Geology, Stockholm University, 10691 Stockholm, Sweden
}

Received 28 June 2011

Accepted 9 September 2011

\begin{abstract}
The application of luminescence dating to young volcanic sediments has been first investigated over three decades ago, but it was only with the technical innovations of the last decade that such analyses became viable. While current analytical procedures show promise for dating late Quaternary volcanic events, most efforts have been aimed at unconsolidated volcanic tephra. Investigations into direct dating of lava flows or of non-heated volcanoclastics like phreatic explosion layers, however, remain scarce. These volcanic deposits are of common occurrence and represent important chrono- and volcanostratigraphic markers. Their age determination is therefore of great importance in volcanologic, tectonic, geomorphological and climate studies. In this article, we propose the use of phreatic explosion deposits and xenolithic inclusions in lava flows as target materials for luminescence dating applications. The main focus is on the crucial criterion whether it is probable that such materials experience complete luminescence signal resetting during the volcanic event to be dated. This is argued based on the findings from existing literature, model calculations and laboratory tests.
\end{abstract}

Keywords: luminescence dating, xenoliths, phreatic explosion, young Quaternary volcanism, geochronology.

\section{INTRODUCTION}

Obtaining accurate numerical ages on young volcanic eruptions is an important issue in geomorphologic, tectonic and climate studies, as well as for volcanic hazard assessments. Unfortunately, methods for directly dating volcanic rocks of Late Pleistocene to Holocene age are rather scarce and possess some inherent pitfalls. Most approaches using radioactive decay systems have stringent requirements such as closed system behaviour, a suitable parent isotope rich constituent and prolonged time to accumulate sufficient radiogenic daughter iso-

Corresponding author: D. Rufer

e-mail: rufer@geo.unibe.ch topes needed for accurate and precise measurements (cf. Faure, 1986). Other methods rely on the presence of datable components difficult to obtain in volcanic environments, for example, sufficient amounts of organic material for radiocarbon dating. An overview of the most established methods is given in Fattahi and Stokes (2003a).

Since the pioneering work of Wintle (1973), the application of luminescence methods to date Late Quaternary volcanic deposits and eruptions has been a recurring topic of research (see table 1 in Fattahi and Stokes, 2003a). Initial investigations were primarily plagued by the occurrence of strong anomalous fading of luminescence signals in volcanic feldspars (Wintle, 1973; Spoon- 
er, 1994; Visocekas and Guerin, 2006) and volcanic quartz (Tsukamoto et al., 2007). The use of volcanic glass - found in almost all volcanic settings - poses the problem that this material exhibits a low signal-to-noise ratio, both in thermoluminescence (TL) and in optically stimulated luminescence (OSL) (Miallier et al., 1991; Berger and Huntley, 1994; Schweitzer, 1997). Investigations into red TL (RTL, e.g. Kanemaki et al., 1991; Miallier et al., 1991) and the development of equipment to measure red IRSL (e.g. Fattahi and Stokes, 2000a; $2000 \mathrm{~b}$ ) allowed to circumvent most of these limitations, including problems with high thermal background (Zink and Visocekas, 1997). However, many issues, e.g. regarding overlapping RTL spectra of volcanic glass, quartz and plagioclase (Kanemaki et al., 1991), still remain. Nonetheless, the cardinal applicability of RTL for dating heated quartz has been demonstrated (e.g. Pilleyre et al., 1992; Miallier et al., 1994a; 1994b) and further methodological advances in recent years have resulted in positioning this technique as a promising tool to date volcanic quartz and feldspar over a wide range of the Quaternary (e.g. Fattahi and Stokes, 2000a; Fattahi and Stokes, 2003b; Tsukamoto et al., 2007).

Most of the conducted studies investigated grains extracted from volcanic tephra layers, either juvenile quartz and feldspar (e.g. Liritzis et al., 1996; Ganzawa et al., 2005; Tsukamoto et al., 2007; Tsukamoto et al., 2010) or non-volcanogenic quartz crystals embedded in the volcanic material during eruption (e.g. Miallier et al., 1994a; Sanzelle et al., 2000; Miallier et al., 2004). Luminescence dating of effusive volcanic events was achieved indirectly by using suitable quartz rich sediments which were capped, heated and thermally reset by lava flows (e.g. Pilleyre et al., 1992; Miallier et al., 1994b; Bassinet et al., 2006). Only a few studies, however, applied luminescence methods to directly date lava flows using plagioclase and quartz (Guerin and Valladas, 1980; Guerin and Petit, 1983; Guerin and Gillot, 2007). Moreover, with the exception of a precursor study by Zöller et al. (2009), no attempts have yet been made to date volcanic deposits in which signal resetting by thermal means is unlikely, as may be the case in phreatic or phreatomagmatic explosion deposits which comprise a substantial fraction of disaggregated country rock. As both lava flows and phreatic or phreatomagmatic eruption deposits form important volcanostratigraphic markers, being able to directly date them would be of great importance.

In spite of the formidable progress in luminescence measurement techniques of volcanic material, one of the crucial problems in most of these approaches remains the control over the composition of the measured material. This problem is manifested by the potentially different luminescence properties of juvenile volcanic minerals and sedimentary derived xenocrysts (e.g. Guerin and Gillot, 2007; Guerin and Samper, 2007) or volcanic glass (e.g. Berger, 1991; Kanemaki et al., 1991). Thus, if the mineral phase to be used for luminescence dating is col- lected from a tephra matrix or a crushed lava, the purity of the sample's volcanic or xenocryst nature is difficult to ascertain, unless the genetic processes of the volcanic unit exclude one of the two. In most continental volcanic settings, this is not the case and will lead to dating problems - particularly when using non single-grain methods - due to varying signal behaviour of individual grains. In order to circumvent these problems, a suitable material do date a Late Pleistocene to Holocene volcanic eruption by luminescence methods should contain only non-volcanic quartz or feldspar, which must have their luminescence signals reset (either thermally or athermally) during the event. Furthermore, to be of importance in terms of applicability, this material should also occur in a wide range of volcanic settings.

In this paper, we present two such materials and the according approaches for dating corresponding volcanic eruptions using luminescence methods. The first approach concerns the dating of phreatic explosion deposits. Arguments for the propensity of non-thermal resetting of country rock material entrained during explosive fragmentation are discussed, and sampling procedures are outlined. The second approach advocates the use of country rock xenoliths emplaced in lava flows in order to derive thermally reset dosimeter grains. The potential for thermal resetting of such volumetric rock bodies emplaced in lava is investigated using numerical modelling and laboratory experiments. Furthermore, important aspects related to the sampling procedure and the extraction of grains for analysis, as well as potential microdosimetry issues are addressed. A first geological case study on phreatic explosion deposits from maar eruptions in the Eifel Volcanic Field (Germany) is presented in Preusser et al. (2011).

\section{DATING OF PHREATIC EXPLOSION DEPOS- ITS}

\section{Occurrence and formation processes of phreatic ex- plosion deposits}

Phreatic to phreatomagmatic eruptions can be found in a wide range of volcanic settings (e.g. Laacher See, 12.9 ka: Schmincke et al., 1999; Krakatoa, 1883: Self and Rampino, 1981; Surtsey, 1963-1965: Thorarinsson, 1967; Jakobsson, 1972). Such eruptions occur through mechanical mixing of magma with water (e.g. at the contact between ascending magma and the phreatic nappe), triggering a chain of reactions resulting in almost instantaneous vaporization and volumetric expansion of large amounts of water ("Molten Fuel Coolant Interaction", e.g. Zimanowski et al., 1991; White, 1996). The ensuing explosions often form distinct volcanosedimentary deposits ranging from proximal high energy surges to distal airfall deposits (Fig. 1, Fig. 2). In the case of phreatic eruptions, which are defined as steam explosions primarily within the country rock above a magmatic heat source (MacDonald, 1972), the ejected mass contains only a 


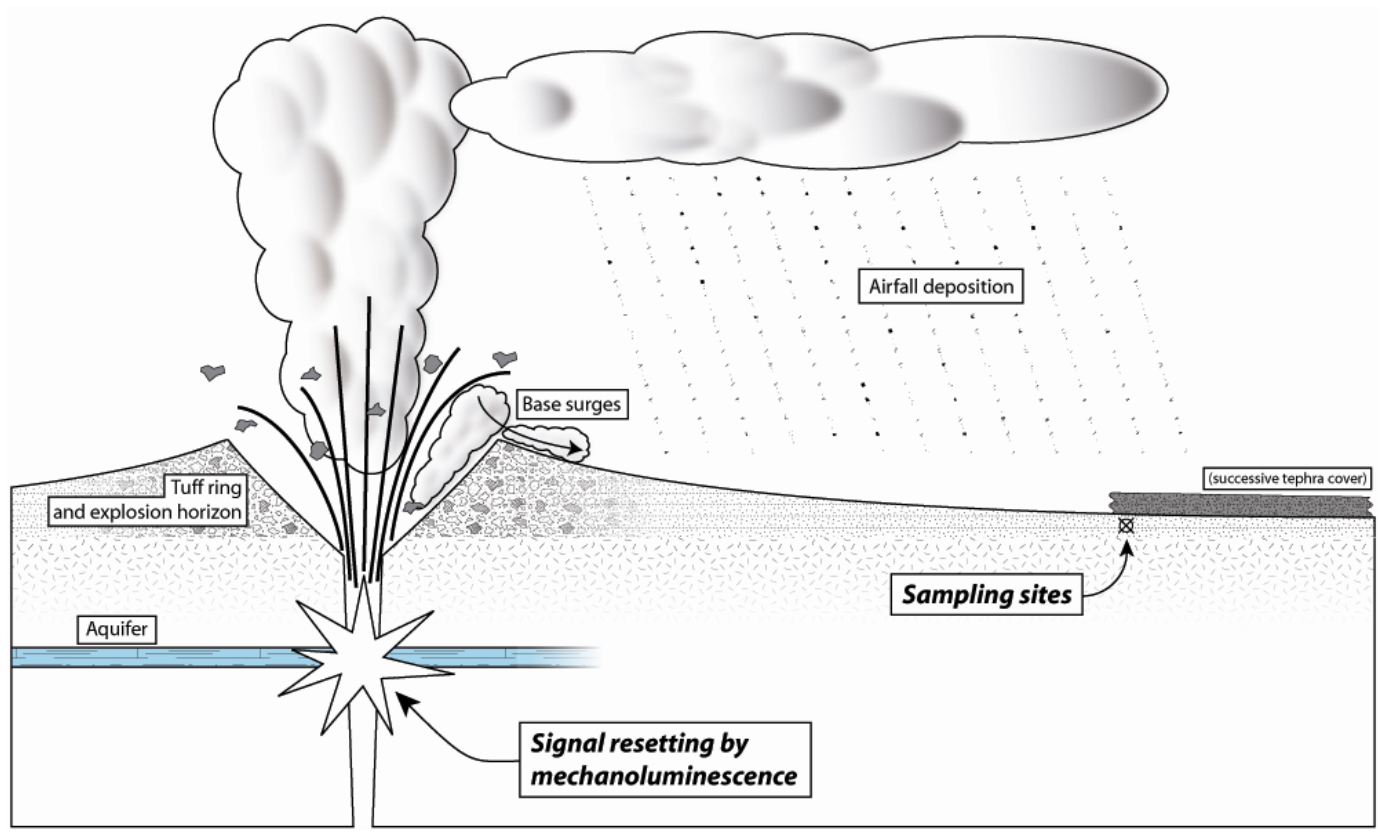

Fig. 1. Schematic crosssection through a phreatic explosion crater with an indication of the relevant sites and processes for luminescence dating of phreatic deposits.

negligible amount of juvenile material, contrary to phreatomagmatic eruptions, where new magma is disintegrated as well. The composition of phreatic explosion deposits can therefore be considered representative of the average basement rock composition. Especially in mafic volcanic provinces dominated by effusive activity, such deposits often provide clearly identifiable correlation horizons which extend far beyond the confined eruption range of cinder cones or fissure vents. As phreatic explosions often occur at the beginning or in early stages of a new eruptive stage, they may provide a means to put a maximum age constraint on a volcanic cycle. This makes them key targets for numerical dating.

\section{The problem of signal resetting in absence of thermal or optical resetting}

Complete optical resetting of phreatic or phreatomagmatic deposits may be unlikely due to the high opacity of the eruption column and possibly rather short aerial transport times - particularly in the case of base surge deposits (e.g. Zöller et al. 2009). There have been suggestions of luminescence and Electron Spin Resonance (ESR) signal resetting by means of (thermally assisted) hydrostatic and dynamic pressure and/or frictional shearing (e.g. Banerjee et al. 1999, and references therein; Zöller et al. 2009), but these findings are mainly based on prolonged high static pressure or combinations of elevated static pressure and mechanical shearing. As such they may not be comparable to the far more dynamic processes occurring during phreatic eruptions. However, Porat et al. (2007) report resetting of OSL signals by earthquake triggered dike-forming injection of clastic material into overlying strata under "several MPa" of hydrostatic pressure and non-elevated temperatures. Sutton (1985), Pres-

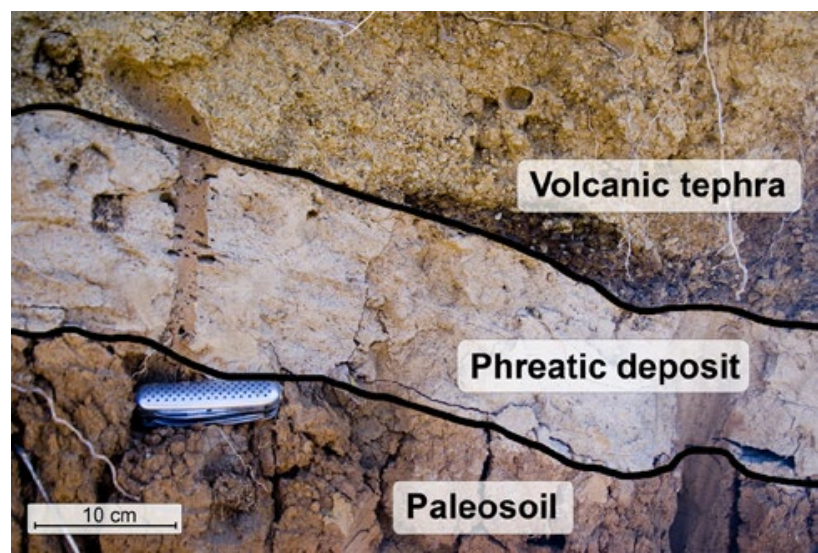

Fig. 2. Outcrop photograph of a phreatic explosion deposit intercalated between a paleosoil from a presumably Tertiary, strongly weathered basaltic lava flow and overlying tephritic tephra. The $\sim 15 \mathrm{~cm}$ thick explosion layer has a sandy grain size and is finely layered; its constituents are derived from granitic rocks. The black lines between the units are for illustrative purposes. Quaternary Ankaratra volcanic field, Central Madagascar.

cott et al. (2004) and Stankowski (2007) present evidence for resetting of TL signals in geological material shocked by meteorite impacts, though the importance of the influence of the mechanical shock versus transient localized heating is still unclear. Finally, Banerjee et al. (1999) showed that short $(<1 \mathrm{~ms})$ pressure pulses elicit mechanoluminescence from fault gouge material proportional to the applied peak pressure above $200 \mathrm{MPa}$ and Sears et al. (1984) present a systematic study of artificially shocked chondrite material, showing both a decrease of natural TL intensity as well as a strong reduction in TL sensitivity in plagioclase for shock waves above $27 \mathrm{GPa}$. Laboratory 
simulations of extremely small-scale phreatomagmatic explosions resulted in pressure pulses of $1.5 \mathrm{~ms}$ between 10 and $100 \mathrm{MPa}$ for melt volumes of only $300 \mathrm{~g}$ and explosion energies of $500 \mathrm{~J}$ (Zimanowski et al., 1991). Though, extrapolating these pressure values for natural eruptions with explosion energies more than 9 orders of magnitude higher (e.g. $10^{10}$ to $10^{12} \mathrm{~J}$, Mt. Usu, Japan, 2000; Yokoo et al., 2002) may not be straightforward, it must also be taken into account that the natural case includes several of these resetting mechanisms in combination.

Besides the theoretical considerations outlined here, case studies demonstrating that mechanical resetting of luminescence signals occurs in phreatic explosions have been provided by Zöller et al. (2009), and will be presented by the authors in forthcoming papers.

\section{Sampling and sample preparation}

In the field, identifying potential layers for sampling requires that they can be causally and geographically linked to the volcanic eruption and the vent which was the source-point of the eruption. The proximal explosion breccia horizon of an explosive eruption can usually be morphologically correlated with the eruptive centre, forming a large part of its tuff-ring. It also allows to determine whether the eruption is of a phreatic nature or not, i.e. based on compositional criteria (e.g. lithic country rock fragments of strongly heterogeneous grain size up to blocks embedded in a fine matrix of the same material) or depositional features (e.g. low-temperature deposition without traces of fusing; poor sorting; bedding structures indicative of turbulent ground transport) (cf. Fischer and Schmincke, 1984; Schmincke, 2004). It can, however, be difficult to sample by conventional methods (e.g. by driving steel tubes into freshly exposed outcrops) due to the abundance of large clasts. Observing stratigraphic and petrographic correlations, it is preferable to sample a more distal facies of such a horizon, where grain sizes are predominantly sandy and sampling can be done in a similar manner to sedimentary material. Scrutinizing the mineral composition of the deposit gives a first indication whether contamination by juvenile volcanic material has to be considered or not. As the thickness of the sampled layer can - based on the ejected volume and the depositional distribution - fall below the minimal thickness required for assuming a homogeneous irradiation environment created by the sampled material itself, it may be necessary to take samples for dose rate determinations from the under- and overlying layers as well. This is particularly important where strong differences in radionuclide contents of palaeosols, crystalline basement material of the explosion layer, or capping volcanic tephra material occur. Sample preparation and measurement can follow standard procedures of sieving, chemical treatment and density separation.

Their chronostratigraphic importance and the rather straightforward sampling and sample preparation tech- niques propound phreatic explosion deposits as an important potential candidate for luminescence dating of late Quaternary volcanic sequences. Due to the nonvolcanic nature of the samples, anomalous fading is expected to be a subordinate problem (Spooner, 1994; Visocekas and Guérin, 2006). However, due to the peculiar, far more violent history of the material compared to, for example, a fluvial derived sediment, it may prove prudent to conduct comprehensive fading tests.

\section{DATING OF THERMALLY RESET XENOLITHS FROM LAVA FLOWS}

Lava flows are common to most volcanic systems and may form important volcanostratigraphic markers. They can be traced back to their source and are more resistant to physical weathering than unconsolidated ejecta. Particularly in mafic volcanic systems, the late stages of an eruptive cycle often are of an effusive nature (e.g. lava ponding and subsequent breakthrough through the scoriae cone rampart). Lava flows may therefore complement an initial or early stage phreatic explosion horizon in providing a minimum age to an eruptive cycle. In terms of luminescence dating they do, however, pose some particular problems, such as the predominantly volcanic origin of the natural dosimeters, the lack of quartz in the volumetrically preponderant mafic suite of volcanic rocks, and technical problems related to the extraction of individual mineral grains from an at least partially glassy matrix.

On the other hand, lava flows often contain xenolithic material, originating from country rock at the vent or taken up during emplacement of the flow (Fig. 3). Provided that the crustal basement material contains luminescence dosimeters, such xenoliths might be used for luminescence dating. They would record the lava flow emplacement as their last heating event. As such xenoliths are cohesive entities, their identification and distinction from the petrographically different volcanic material is facilitated and any grains extracted from them certainly are of non-volcanic origin. Xenoliths may provide datable material even in situations where the volcanic rocks themselves are devoid of quartz or feldspar. They also allow circumventing the issue of impure mixtures of volcanic and non-volcanic dosimeter grains as well as of problems specifically associated with volcanic dosimeters.

\section{Sampling and sample preparation}

As the outermost parts of the xenolith will have to be cut away in order to avoid contamination with adherent volcanic material and to remove optically reset surface grains, selecting a specimen of at least 5 to $10 \mathrm{~cm}$ in diameter is recommended. Fortunately, this also allows sample collection without any special consideration regarding sunlight exposure. When extracting a xenolith from the lava, it is necessary to also take a representative 
sample of the volcanic material for dosimetry considerations.

Xenolith samples must be disaggregated prior to any standard sample preparation methods (which are normally applied to unconsolidated samples). A suitable generalized procedure is given in Fig. 4. Sample disaggregation has to be non-detrimental to the type of signal that is to be measured. It must therefore be done under laboratory red light, and it is important that cutting with a diamond blade has to be done very slowly and under copious amounts of cold water in order to prevent heating of the sample. Concerning the subsequent breaking and crushing of the slabs, Zöller et al. (2009) report that "vigorous grinding" for 15 minutes in an agate mortar may lead to

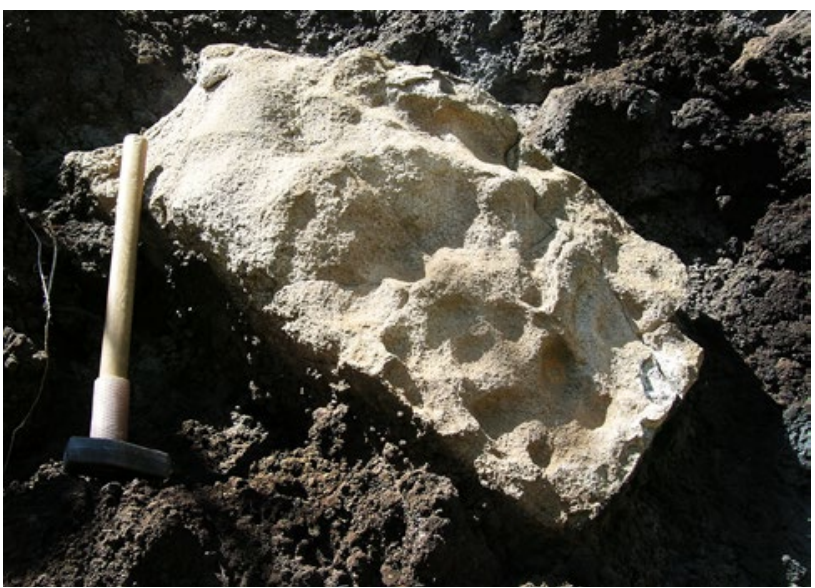

Fig. 3. Syenogranite xenolith embedded in a proximal basanitic lava flow (Lac Tritriva, central Madagascar; length of hammer is $60 \mathrm{~cm}$ ). The light appearance is due to calcination of the feldspar and oxidation of the mica minerals.

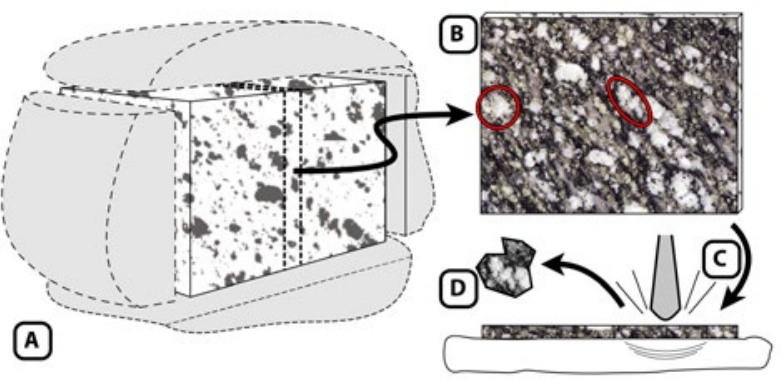

Fig. 4. Generalized procedure for extracting mineral grains for luminescence measurements from hard rocks. A) Any exposed outer parts are removed and $B$ ) the remaining material is cut into thin slabs of a few $\mathrm{mm}$ thickness. After identifying and marking target mineral grains, the slab is placed on a flexible pad and manually cracked using a constant application of force $(C)$. The pieces containing the marked grains (D) are then gently crushed in an agate mortar and sieved to the desired grain size spectrum. If required, the obtained material can be further processed by density separation and chemical treatments, as necessitated by the intended use. If the extracted mineral phase is quartz, treatment with $\mathrm{H}_{2} \mathrm{FSi}_{6}$ for at least several days is advisable to remove any contaminant feldspar (cf. Mauz and Lang, 2004). an increased natural TL signal due to triboluminescence. This might be related, however, to the concomitant intense frictional shearing, as Tsukamoto et al. (2011) did not find any evidence for decreasing IRSL luminescence signals due to crushing.

\section{Thermal resetting of samples during emplacement}

Successful TL dating of volcanic units using embedded xenoliths prerequisites a complete thermal resetting of the luminescence signal during or shortly after the incorporation of the xenolith into the volcanic material. To achieve this by bulk heating of the xenolith, the latter has to be subjected to a sufficiently high ambient temperature to bleach the luminescence signal to be investigated $\left(>450^{\circ} \mathrm{C}\right.$ for most of the conventional TL, OSL and IRSL methods on quartz or feldspar).

For (non-carbonatitic) lava flows, emplacement temperatures generally range between 750 to $1200^{\circ} \mathrm{C}$, as a function of chemical composition (Rittmann, 1981). Flow surface cooling rates for a $20-70 \mathrm{~m}$ thick rhyolitic flow of Mayor Island (NZ) are given between 0.001 and $6^{\circ} \mathrm{C} \min ^{-1}$ with the majority of the data around $0.001{ }^{\circ} \mathrm{C} \mathrm{min}{ }^{-1}$ (Gottsmann and Dingwell, 2002). For basaltic compositions, Flynn and Mouginis-Mark (1992) report cooling of the thin surface crust of a very small volume ( $2 \mathrm{~m}$ wide, $3 \mathrm{~m}$ long, $30 \mathrm{~cm}$ thick) flow from the Pu'u O'o fissure, Kilauea, Hawaii, from 768 to $390^{\circ} \mathrm{C}$ over a period of 59 minutes after emplacement. During the same period, temperatures just below the cooling crust stayed between 1150 and $900^{\circ} \mathrm{C}$. This indicates that most parts of a lava flow will, regardless of its composition, retain temperatures significantly exceeding the bleaching temperatures for most luminescence dating approaches for a prolonged amount of time.

\section{Volume heating model and calefaction experiments}

In order to verify the assumption that a xenolith embedded in such a lava flow will be thermally reset, a numerical model was calculated to simulate the temperature profile over time within a granite cube coming into contact with hot lava. The model granite cube is approximately the size of a hand specimen, having an edge length of $7 \mathrm{~cm}$ and a density of $2.75 \mathrm{~g} \mathrm{~cm}^{-3}$. Heat transfer towards the core of the cube is governed by Fourier's law of thermal conduction (e.g. Cannon, 1984), using a specific heat capacity for granite of $0.79 \mathrm{~kJ} \mathrm{~kg}^{-1} \mathrm{~K}^{-1}$ and a thermal conductivity of $2.25 \mathrm{~W} \mathrm{~m}^{-1} \mathrm{~K}^{-1}$, which is close to the lower boundary of the range of thermal conductivity values reported for dry granite $\left(2.12\right.$ to $3.12 \mathrm{~W} \mathrm{~m}^{-1} \mathrm{~K}^{-1}$; Cho et al., 2009).

At the start of the model, the cube's temperature is at $20^{\circ} \mathrm{C}$ and its surface temperature is set to $800^{\circ} \mathrm{C}$, simulating the instantaneous temperature rise in an infinitely thin surface layer upon contact with $800^{\circ} \mathrm{C}$ hot lava. This surface temperature is kept constant during the simulation, assuming that any cooling of the lava by the xeno- 
lith will be insignificant, considering the very low ratio between the small volume of a "cool" xenolith and the large volume of the surrounding lava, the corresponding heat contents and the already mentioned low temperature decrease of lava flows in the time range of a few minutes to a few hours.

Fig. 5 shows a central section of the modelled granite cube at A) 260 seconds, when the temperature at the core of the cube exceeds $450^{\circ} \mathrm{C}$ and B) 880 seconds, when the entire volume of the cube is within $10^{\circ} \mathrm{C}$ of the lava temperature. These results show that a similarly sized xenolith which becomes embedded in an only $800^{\circ} \mathrm{C}$ hot lava flow (close to the lower end of the temperature range for lava flows, Rittmann, 1981) would be completely thermally reset in less than five minutes. When using the same model with a cube of $50 \mathrm{~cm}$ edge length, complete thermal resetting would still be attained within less than 3.6 hours. Considering that the selected values for the lava temperature and the granite's thermal conductivity are close to the lower boundary of their respectively reported ranges, the model results must be interpreted as maximum times required for thermal resetting.

A complementary laboratory calefaction test was conducted on two porphyritic granite cubes from the Hercynian age (320-280 Ma) central Aar massif, Switzerland, (Steck, 1968), featuring prominent, cm-sized K-feldspar grains. The cubes were put into an oven preheated at $800^{\circ} \mathrm{C}$ and heated for 30 and 60 minutes respectively. Immediately afterwards, they were removed from the oven and let to cool at room temperature. A third cube was not heated, but otherwise treated identically in order to serve as a non-reset comparative piece. The dimension of the cubes was identical to the numerical model. It must be noted that the conditions of the calefaction experiment are not the same as the conditions of the model, as inside the oven the blocks are embedded in air. Heat transfer onto the granite is therefore not primarily conductive, but is dominated by convection (heat transfer from the hot air to the granite) and radiation (heat transfer from the glowing oven walls to the granite). This results in a lower total
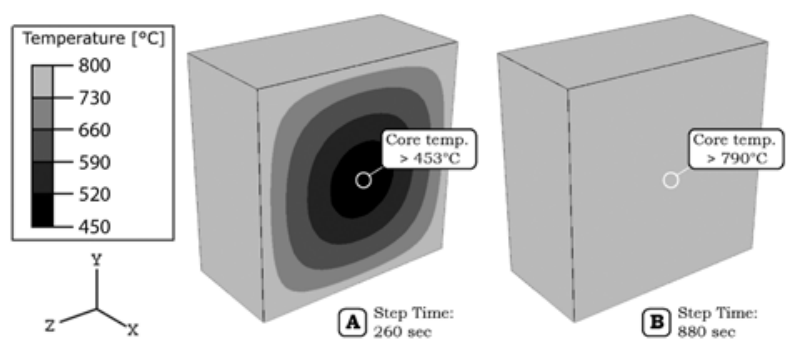

Fig. 5. Model of conductive heat distribution in a granite cube of $7 \mathrm{~cm}$ edge length (centre cross-section) when exposed to $800^{\circ} \mathrm{C}$ hot lava. The cube's core temperature exceeds $450^{\circ} \mathrm{C}$ after less than 5 minutes and is close to the lava temperature after less than 15 minutes, indicating that complete thermal resetting will be achieved. For model parameters and boundary conditions, see text. heat flux compared to the numerical model, where the surface is in direct contact with the hot lava. Irrespective of this, the cubes were glowing in the bright red to orange spectrum after 30 minutes, indicative of temperatures above $800^{\circ} \mathrm{C}$. As such, this is roughly comparable to the model situation.

After cooling, several of the large K-feldspar grains were extracted from near the surface and from the core of the cubes (according to the sample preparation procedure outlined in this article, followed by standard chemical treatment and density separation as given in Preusser et al., 2008) in order to verify their complete thermal resetting. The TL measurements were conducted on a Risø DA-20 TL/OSL reader, fitted with an internal ${ }^{90} \mathrm{Sr} /{ }^{90} \mathrm{Y}$ beta-source and using an interference filter in combination with a $1 \mathrm{~mm}$ Schott BG39 (the latter serving as a heat protection). A short TL-SAR protocol with two regenerative dose points - similar to the one suggested by Richter and Krbetschek (2006) - was used to measure the bleached samples. The non-bleached sample material was similarly measured, but with additional, higher regenerative dose points (Table 1).

The obtained results are given in Table 2 and clearly show that complete thermal resetting was already reached after 30 minutes, with the measured $D_{e}$ of the tempered samples clustering close to zero (averages of $0.03 \pm 0.19 \mathrm{~Gy}[\mathrm{n}=3]$ and $0.02 \pm 0.19 \mathrm{~Gy}[\mathrm{n}=3]$ for surface and core grains, respectively). The signal was integrated

Table 1. Outline of the measurement protocol used in the calefaction experiments.

\begin{tabular}{ll}
\hline Step & Action \\
\hline 1 & aGive dose $\mathrm{Di}_{\mathrm{i}}$ \\
2 & Preheat to $220^{\circ} \mathrm{C} ; 5^{\circ} \mathrm{C} \mathrm{s}^{-1}$ \\
3 & TL to $450^{\circ} \mathrm{C} ; 5^{\circ} \mathrm{C} \mathrm{s}^{-1}$ \\
4 & Give dose $\mathrm{D}_{\mathrm{t}}(15.6 \mathrm{~Gy})$ \\
5 & Preheat to $220^{\circ} \mathrm{C} ; 5^{\circ} \mathrm{C} \mathrm{s}{ }^{-1}$ \\
6 & TL to $450^{\circ} \mathrm{C} ; 5^{\circ} \mathrm{C} \mathrm{s}^{-1}$ \\
\hline
\end{tabular}

aFor the natural sample, $i=0$ and $D_{0}$ is the natural dose; for the doseresponse curve, $i=1-4$ and $D_{1-4}$ are $10.4 \mathrm{~Gy}, 20.8 \mathrm{~Gy}, 0$ Gy and 10.4 Gy (as such including the zero-dose and recycling step). For the non-bleached samples $i=1-9$ and $D_{1-9}$ are $10.4 \mathrm{~Gy}, 20.8 \mathrm{~Gy}$, 31.2 Gy, 72.7 Gy, 124.6 Gy, 259.6 Gy, 519.3 Gy, 0 Gy and 10.4 Gy.

Table 2. Equivalent dose $\left(D_{e}\right)$ determinations of the calefaction test.

\begin{tabular}{lcccc}
\hline & & Block I (30 min.) & Block II (60 min.) & Blank block \\
\hline Surface & (Gy): & $0.03 \pm 0.19$ & $0.03 \pm 0.21$ & n.d. \\
Core & (Gy): & $0.02 \pm 0.19$ & $0.03 \pm 0.23$ & saturated \\
\hline
\end{tabular}

$D_{e}$ values are given as average of three aliquots with propagated measurement errors. Complete thermal resetting of both surface and core derived grains after tempering for only 30 minutes is in accord with the results from the numerical model and substantiates the thermal resetting of small xenoliths embedded in lava flows. For experimental setup, see text. 
between $270^{\circ} \mathrm{C}$ and $360^{\circ} \mathrm{C}$ with a background between $20^{\circ} \mathrm{C}$ and $100^{\circ} \mathrm{C}$. Recycling ratios are within $13 \%$ of unity and the sensitivity change over the SAR sequence remained below $20 \%$ for the tempered samples but is $>60 \%$ for the non-tempered material. The TL glow curves and the SAR dose response curve for the material extracted from the core of the 30 minute tempered block are shown in Fig. 6. The results for the block tempered for 60 minutes are identical. Using regeneration doses up to $520 \mathrm{~Gy}$, the natural signal of the non-tempered sample remained significantly above the laboratory saturation level. The observed oversaturation might be explained by the large sensitivity change in the unheated material. With the calefaction experiment showing that complete thermal bleaching of the granite cubes is reached in less than 30 minutes, it corroborates the numerical model.

Based on these findings, thermal resetting of comparably small xenoliths during emplacement in a lava flow is to be expected. Considering the very conservative parameter-values used in the model, the fact that lava temperatures are usually higher and that cooling rates are far lower in the natural case than in the calefaction experiment, xenoliths even exceeding the size of what can be conveniently sampled in the field can be considered to be thermally reset. As an example of this, Fig. 3 shows a syenogranitic xenolith of an estimated volume of over $0.3 \mathrm{~m}^{3}$ with its shortest dimension exceeding $30 \mathrm{~cm}$, embedded in a several meter thick basanitic lava flow. The biotite throughout the xenolith evidences distinct petrographic signs of advanced to complete oxidation, denoting temperatures exceeding $670^{\circ} \mathrm{C}$ (Chandra and Lokanathan, 1982), while the potassium feldspar shows signs of calcination, indicative of temperatures above approximately $800^{\circ} \mathrm{C}$ (e.g. Feng and Ma, 2004).

\section{Microdosimetric considerations when measuring coarse grained, solid materials}

The configuration of a crystalline xenolith in a more or less homogeneous volcanic matrix material poses some profound complications in establishing effective dose rates. External dose contributions to a specific mineral grain originate both from the xenolith material itself, as well as from the volcanic matrix material surrounding the xenolith. While the latter may be reduced to mainly gamma radiation due to shielding by the rock material between the target grain and the lava, the former is dependent on the mineralogical composition of the xenolith. Being an aggregate of unequally sized mineral grains with potentially different radiation emissions (e.g. inert quartz, large radiation emitters like potassium feldspars or small, highly radiating accessory minerals like zircons or monazites), the spatial dosimetry field of a xenolith might be strongly heterogeneous. Detection of such inhomogeneities is therefore of great importance for discerning potentially problematic samples or to specifically select mineral grains from dosimetrically homogeneous regions of a xenolith. For a detailed discourse of this topic and an analytical approach see Rufer and Preusser (2009).

\section{SUMMARY AND OUTLOOK}

We have outlined two potential candidate materials for dating young Quaternary volcanic events and discussed their cardinal usability for luminescence dating. Both, phreatic explosion deposits as well as crustal xenoliths in lava flows are common to most continental vol-
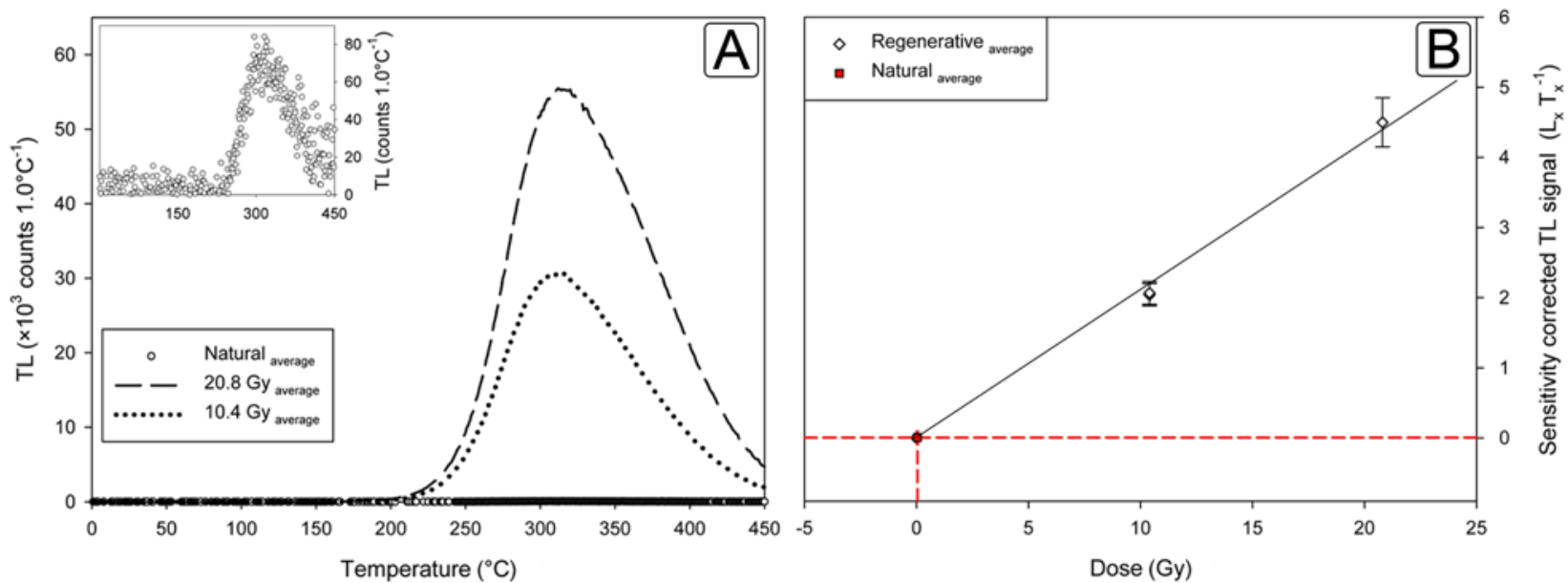

Fig. 6. A) TL glow curve of the natural (inset) and the regenerative signals from the calefaction experiment. Shown are the average curves of 3 aliquots from a feldspar grain extracted from the core of the cube after tempering for 30 minutes at $800^{\circ} \mathrm{C}$. Please note that the scaling in the inset is three magnitudes lower. B) Corresponding SAR dose response curve using a linear fit. Integrated temperature ranges: signal $=270-360^{\circ} \mathrm{C}$, background $=20-100^{\circ} \mathrm{C} ; D_{e}=0.02 \pm 0.19 \mathrm{~Gy}$; recycling $=1.02 \pm 0.11$; sensitivity change during SAR sequence $=<20 \%$. 
canic systems, making the proposed dating approaches potentially applicable to a large number of sites. With the exception of a precursor study by Zöller et al. (2009), and a first independent case study on phreatic explosion deposits from the Eifel Volcanic Field (Germany) by Preusser et al. (2011), actual luminescence dating of such materials is as yet outstanding. However, as determining numerical ages of Late Quaternary volcanic deposits is of crucial importance to a wide range of scientific disciplines, these new approaches can help to expand on the variety of datable archives and therefore warrant further detailed investigation.

\section{ACKNOWLEDGEMENTS}

M. Suchy, S. Lowick, and I. Schindelwig are thanked for helpful comments on the manuscript. We gratefully acknowledge S. Tsukamoto and the anonymous reviewer for critical reviewing of the manuscript. This work was funded by the Swiss National Science Foundation (SNSF), Project No's 200020-105453/1, 200020-118023/1 and 206021-117374.

\section{REFERENCES}

Banerjee D, Singhvi AK, Pande K, Gogte VD and Chandra BP, 1999. Towards a direct dating of fault gouges using luminescence dating techniques - Methodological aspects. Current Science 77(2): 256268.

Bassinet C, Mercier N, Miallier D, Pilleyre T, Sanzelle S and Valladas $\mathrm{H}, 2$ 2006. Thermoluminescence of heated quartz grains: Intercomparisons between SAR and multiple-aliquot additive dose techniques. Radiation Measurements 41(7-8): 803-808, DOI 10.1016/j.radmeas.2006.04.013.

Berger GW, 1991. The use of glass for dating volcanic ash by thermoluminescence. Journal of Geophysical Research-Solid Earth 96(B12): 19705-19720, DOI 10.1029/91JB01899.

Berger GW and Huntley DJ, 1994. Tests for optically stimulated luminescence from tephra glass. Quaternary Science Reviews 13(5-7): 509-511, DOI 10.1016/0277-3791(94)90067-1.

Cannon J, 1984. The one-dimensional heat equation. Addison-Wesley, Menlo Park: 483pp.

Chandra U and Lokanathan S, 1982. A Mössbauer study of the effect of heat-treatment on biotite micas. Journal of Physics D - Applied Physics 15(11): 2331-2340.

Cho WJ, Kwon S and Choi JW, 2009. The thermal conductivity for granite with various water contents. Engineering Geology 107(34): 167-171, DOI 10.1016/j.enggeo.2009.05.012.

Fattahi $\mathrm{M}$ and Stokes S, 2000a. Extending the time range of luminescence dating using red TL (RTL) from volcanic quartz. Radiation Measurements 32(5-6): 479-485, DOI 10.1016/S13504487(00)00105-0.

Fattahi M and Stokes S, 2000b. Red thermoluminescence (RTL) in volcanic quartz: development of a high sensitive detection system and some preliminary findings. Ancient TL 18(2): 35-44.

Fattahi $\mathrm{M}$ and Stokes S, 2003a. Dating volcanic and related sediments by luminescence methods: a review. Earth-Science Reviews 62(34): 229-264, DOI 10.1016/S0012-8252(02)00159-9.

Fattahi M and Stokes S, 2003b. Photomultiplier and filter combinations for the detection of relatively long wavelength $(>600 \mathrm{~nm})$ luminescence emissions from feldspar. Ancient TL 21(1): 25-34.

Faure G, 1986. Principles of isotope geology, $2^{\text {nd }}$ edition. John Wiley and Sons, New York: 589pp.
Feng $\mathrm{W}$ and $\mathrm{Ma} \mathrm{H}, 2004$. Thermodynamic analysis and experiments of thermal decomposition for potassium feldspar at intermediate temperatures. Journal of the Chinese Ceramic Society 32(7): 789-799.

Fischer RV and Schmincke HU, 1984. Pyroclastic rocks. Springer Verlag, Berlin: 472pp.

Flynn LP and Mouginis-Mark PJ, 1992. Cooling rate of an active Hawaiian lava flow from nighttime spectroradiometer measurements. Geophysical Research Letters 19(17): 1783-1786, DOI 10.1029/92GL01577.

Ganzawa Y, Furukawa H, Hashimoto T, Sanzelle S, Miallier D and Pilleyre T, 2005. Single grains dating of volcanic quartz from pyroclastic flows using red TL. Radiation Measurements 39(5): 479487, DOI 10.1016/j.radmeas.2004.10.012.

Gottsmann J and Dingwell DB, 2002. The thermal history of a spatterfed lava flow: the 8-ka pantellerite flow of Mayor Island, New Zealand. Bulletin of Volcanology 64(6): 410-422, DOI 10.1007/s00445-002-0220-7.

Guerin G and Valladas G, 1980. Thermo-luminescence dating of volcanic plagioclases. Nature 286(5774): 697-699, DOI $10.1038 / 286697 \mathrm{a} 0$

Guerin G and Petit RH, 1983. Thermo-luminescence dating of lava flows from Guadeloupe - Some Problems. Comptes Rendus de L'Academie des Sciences Serie II 296(23): 1791-1794.

Guerin G and Samper A, 2007. Aberrant thermoluminescence dates obtained from primary volcanic quartz. Radiation Measurements 42(9): 1453-1459, DOI 10.1016/j.radmeas.2007.03.006.

Guerin G and Gillot PY, 2007. New elements of chronology of 'Bas Vivarais' Pleistocene volcanism (Ardèche, France) by thermoluminescence dating. Comptes Rendus Geoscience 339(1): 40-49, DOI 10.1016/j.crte.2006.10.005.

Jakobsson SP, 1972. On the consolidation and palagonitization of the tephra of the Surtsey volcanic island, Iceland. Surtsey Research Progress Report,VI: 121-128.

Kanemaki M, Ninagawa K, Yamamoto I, Nakagawa M, Wada T, Yamashita Y and Endo K, 1991. Red thermoluminescence of volcanic glass fractions from tephras. Nuclear Tracks and Radiation Measurements 18(1-2): 81-88, DOI 10.1016/1359-0189(91)90097-

Liritzis I, Michael C and Galloway RB, 1996. A significant Aegean volcanic eruption during the second millennium B.C. revealed by thermoluminescence dating. Geoarchaeology 11(4): 361-371, DOI 10.1002/(SICI)1520-6548(199607)11:4<361::AIDGEA4>3.0.CO;2-\#

MacDonald GA, 1972. Volcanoes. Prentice-Hall, Englewood Cliffs NJ: 510 pp.

Mauz B and Lang A, 2004. Removal of the feldspar-derived luminescence component from polymineral fine silt samples for optical dating applications: evaluation of chemical treatment protocols and quality control procedures. Ancient TL 22(1): 1-9.

Miallier D, Fain J, Montret M, Pilleyre T, Sanzelle S and Soumana S, 1991. Properties of the red TL peak of quartz relevant to thermoluminescence dating. Nuclear Tracks and Radiation Measurements 18(1-2): 89-94, DOI 10.1016/1359-0189(91)90098-3.

Miallier D, Fain J, Sanzelle S, Pilleyre T, Montret M, Soumana S and Falgueres C, 1994a. Attempts at dating pumice deposits around $580-\mathrm{Ka}$ by use of red TL and ESR of xenolithic quartz inclusions. Radiation Measurements 23(2-3): 399-404, DOI 10.1016/13504487(94)90070-1.

Miallier D, Sanzelle S, Falgueres C, Fain J, Montret M, Pilleyre T, Soumana S, Laurent M, Camus G and Deherve AD, 1994b. Intercomparisons of red TL and ESR signals from heated quartz grains. Radiation Measurements 23(1): 143-153, DOI 10.1016/13504487(94)90031-0.

Miallier D, Condomines M, Pilleyre T, Sanzelle S and Guittet J, 2004. Concordant thermoluminescence and U-238-Th-230 ages for a trachytic dome (Grand Sarcoui) from the Chaîne des Puys (French Massif Central). Quaternary Science Reviews 23(5-6): 709-715, DOI 10.1016/j.quascirev.2003.06.002.

Pilleyre T, Montret M, Fain J, Miallier D and Sanzelle S, 1992. Attempts at dating ancient volcanos using the red TL of quartz. Qua- 
ternary Science Reviews 11(1-2): 13-17, DOI 10.1016/02773791(92)90036-8.

Porat N, Levi T and Weinberger R, 2007. Possible resetting of quartz OSL signals during earthquakes - Evidence from late Pleistocene injection dikes, Dead Sea basin, Israel. Quaternary Geochronology 2(1-4): 272-277, DOI 10.1016/j.quageo.2006.05.021.

Prescott JR, Robertson GB, Shoemaker C, Shoemaker EM and Wynn J, 2004. Luminescence dating of the Wabar meteorite craters, Saudi Arabia. Journal of Geophysical Research-Planets 109(E1): 1-8, DOI 10.1029/2003JE002136.

Preusser F, Degering D, Fuchs M, Hilgers A, Kadereit A, Klasen N, Krbetschek M, Richter D and Spencer QG, 2008. Luminescence dating: basics, methods and applications. E\&G / Quaternary Science Journal, 57(1-2): 95-149, DOI 10.3285/eg.57.1-2.5.

Preusser F, Rufer D and Schreurs G, 2011. Direct dating of Quaternary phreatic maar eruptions by luminescence methods. Geology 39: 1135-1138, DOI 10.1130/G32345.1.

Richter D and Krbetschek M, 2006. A new thermoluminescence dating technique for heated flint. Archaeometry 48(4): 695-705, DOI 10.1111/j.1475-4754.2006.00281.x.

Rittmann A, 1981. Vulkane und ihre Tätigkeit. Ferdinand Enke Verlag Stuttgart

Rufer D and Preusser F, 2009. Potential of autoradiography to detect spatially resolved radiation patterns in the context of trapped charge dating. Geochronometria 34: 1-13. DOI 10.2478/v10003009-0014-4.

Sanzelle S, Pilleyre T, Montret M, Fain J, Miallier D, Camus G, de Herve $\mathrm{AD}$ and Defleur A, 2000. Thermoluminescence dating: study of a possible chronological correlation between the maar of La Vestide-du-Pal and a tephra layer from La Baume-MoulaGuercy (Ardeche, France). Comptes Rendus de L'Academie des Sciences, Serie II, Fascicule a-Sciences de la Terre et des Planètes 330(8): 541-546.

Schmincke HU, Park C and Harms E, 1999. Evolution and environmental impacts of the eruption of Laacher See Volcano (Germany) 12,900 a BP. Quaternary International 61(1): 61-72, DOI 10.1016/S1040-6182(99)00017-8.

Schmincke HU, 2004. Volcanism. Springer Verlag, Berlin: 334pp.

Schweitzer U, 1997. Thermolumineszenz-Datierbarkeit vulkanischer Gläser des Thera-Vulkans (Santorin-Archipel, Griechenland). (On the datability of volcanic glass of the Thera volcano (Santorin archipelago, Greece) using thermoluminescence). PhD-Thesis, University of Cologne, Cologne.

Sears DW, Ashworth JR, Broadbent CP and Bevan AWR, 1984. Studies of an artificially shock-loaded H-group chondrite. Geochimica Et Cosmochimica Acta 48(2): 343-360.

Self S and Rampino MR, 1981. The 1883 eruption of Krakatau. Nature 294(5843): 699-704, DOI 10.1038/294699a0.

Spooner NA, 1994. The Anomalous Fading of Infrared-Stimulated
Luminescence from Feldspars. Radiation Measurements 23(2-3): 625-632, DOI 10.1016/1350-4487(94)90111-2.

Stankowski WTJ, 2007. Luminescence dating as a diagnostic criterion for the recognition of Quaternary impact craters. Planetary and Space Science 55(7-8): 871-875, DOI 10.1016/j.pss.2006.11.006.

Steck A, 1968. Die alpidischen Strukturen in den Zentralen Aaregraniten des westlichen Aarmassivs (The alpine structures in the central Aar-granites of the western Aar-massif). Eclogae Geologicae Helvetiae 61, 19-48.

Sutton SR, 1985. Thermo-luminescence measurements on shockmetamorphosed sandstone and dolomite from Meteor Crater, Arizona. 1. Shock dependence of thermo-luminescence properties. Journal of Geophysical Research-Solid Earth and Planets 90(B5): 3683-3689, DOI 10.1029/JB090iB05p03683.

Thorarinsson S, 1967. The Surtsey eruption. Course of events during the year 1966. Surtsey Research Progress Report III: 84-90.

Tsukamoto S, Murray AS, Huot S, Watanuki T, Denby PM and BotterJensen L, 2007. Luminescence property of volcanic quartz and the use of red isothermal TL for dating tephras. Radiation Measurements 42(2): 190-197, DOI 10.1016/j.radmeas.2006.07.008.

Tsukamoto S, Duller GAT, Wintle AG and Frechen M, 2010. Optical dating of a Japanese marker tephra using plagioclase. Quaternary Geochronology 5: 274-278, DOI 10.1016/j.quageo.2009.02.002.

Tsukamoto S, Duller GAT, Wintle AG and Muhs D, 2011. Assessing the potential for luminescence dating of basalts. Quaternary Geochronology 6(1): 61-70, DOI 10.1016/j.quageo.2010.04.002.

Visocekas R and Guerin G, 2006. TL dating of feldspars using their farred emission to deal with anomalous fading. Radiation Measurements 41(7-8): 942-947, DOI 10.1016/j.radmeas.2006.04.023.

White JDL, 1996. Impure coolants and interaction dynamics of phreatomagmatic eruptions. Journal of Volcanology and Geothermal Research 74(3-4): 155-170, DOI 10.1016/S0377-0273(96)000613.

Wintle AG, 1973. Anomalous fading of thermoluminescence in mineral samples. Nature 245(5421): 143-144, DOI 10.1038/245143a0.

Yokoo A, Taniguchi H, Goto A and Oshima H, 2002. Energy and depth of Usu 2000 phreatic explosions. Geophysical Research Letters 29(24), 2195, DOI 10.1029/2002GL015928.

Zimanowski B, Frohlich G and Lorenz V, 1991. Quantitative experiments on phreatomagmatic explosions. Journal of Volcanology and Geothermal Research 48(3-4): 341-358, DOI 10.1016/0377-0273(91)90050-A.

Zink AJC and Visocekas R, 1997. Datability of sanidine feldspars using the near-infrared TL emission. Radiation Measurements 27(2): 251-261, DOI 10.1016/S1350-4487(96)00141-2.

Zöller L, Blanchard $\mathrm{H}$ and McCammon C, 2009. Can temperature assisted hydrostatic pressure reset the ambient TL of rocks? - A note on the TL of partially heated country rock from volcanic eruptions. Ancient TL 27(1): 15-23. 